\title{
LA COLECCIÓN GOYA-MALABRIGO DEL MUSEO MUNICIPAL REGIONAL DE LA PAZ (PROVINCIA DE ENTRE RÍOS)
}

\author{
Flavia V. Ottalagano ${ }^{1}$
}

En este anexo presentamos los materiales arqueológicos asociados a la entidad arqueológica Goya-Malabrigo, relevados por Carlos Ceruti hace casi cuatro décadas. El original mecanografiado por el autor fue terminado de elaborar en junio de 1980, permaneciendo inédito. Las piezas arqueológicas forman parte de la colección depositada en el Museo Municipal Regional "Alicia Gonzáles Castrillón", situado en la ciudad de La Paz, en la provincia de Entre Ríos, al nordeste de Argentina (Figura 1 y 2). Esta institución comienza a funcionar en 1976, y recibe el aporte de materiales arqueológicos donados por particulares, como es el caso de los registrados en el presente relevamiento.

Aquí publicamos una selección de 31 piezas arqueológicas, de las 48 relevadas. Corresponden principalmente a apéndices zoomorfos de cerámica que en su mayoría representan cabezas de aves psitaciformes -posiblemente del género Ara, como ha sido argumentado en Ottalagano (2008)-, aunque también se registran algunas representaciones de aves strigiformes, así como de algunos mamíferos como primates, pecaries y felinos.

La elaboración de asas figurativas es considerada uno de los aspectos centrales del estilo Goya-Malabrigo (Caggiano 1984; Ceruti 2003; González 1977; Rodríguez 1992; Serrano 1946, 1958). Su presencia en el registro arqueológico se constata a lo largo de todo el Paraná medio, y también en parte del Paraná inferior y del río Uruguay (Ceruti 2003). Estas asas estuvieron incorporadas a vasijas de diversas formas y tamaños, y han formado parte asimismo de las denominadas "campanas" o "alfarerias gruesas" (Gaspary 1950; Serrano 1958), algunas de las cuales se exhiben en este relevamiento. Las "campanas", cuya funcionalidad aún no ha podido ser precisada, son consideradas igualmente propias del estilo cerámico Goya-Malabrigo, y se caracterizan entre otras cosas por presentar paredes extremadamente gruesas $\mathrm{y}$ al menos dos aberturas: una superior y otra basal.

E1 relevamiento incluye, además, la descripción de tres alfarerias miniaturas, artefactos frecuentes en el registro regional Goya-Malabrigo, así como también restos de vasijas lisas o decoradas mediante pintura roja y/o por medio de incisiones. Completan el relevamiento, por último, la descripción de dos torteros de cerámica, una probable pesa para red y dos artefactos líticos.

La gran mayoría de las piezas descriptas en este anexo proceden de dos sitios paradigmáticos para la ocupación humana prehispánica en el Paraná medio: Arroyo Las Mulas I y Arroyo Largo I, ambos localizados en las inmediaciones de la ciudad de La Paz (Figura 2). El primero fue investigado a partir de la década de 1920 desde el Museo Provincial de Entre Ríos (actualmente Museo de Ciencias Naturales y An-

1 CONICET- Instituto Nacional de Antropología y Pensamiento Latinoamericano;

flaviaott7@gmail.com 
tropológicas "Prof. Antonio Serrano", ubicado en la ciudad de Paraná), bajo la guía del propio Serrano y de Víctor Badano, y fue excavado intensamente a mediados de la década de 1940 (Serrano 1946). Posteriormente, las investigaciones en Arroyo Las Mulas I fueron continuadas por Ceruti (1984, 1989, 1990, 1991, 2003), quien registró diversos entierros humanos, asî como abundante alfarería, artefactos líticos, óseos y restos arqueofaunísticos, con una cronología de $950 \pm 120$ años a.p. Arroyo Largo I, por su parte, fue relevado tempranamente por Serrano y Badano, y excavado por Ceruti (1984, 1989, 2003) entre las décadas de 1970 y 1980, demos- trando la presencia de dos componentes con cronologias respectivas de $1380 \pm 100$ y $900 \pm 120$ años a.p.

Una sola pieza arqueológica de este anexo proviene del sitio Arroyo Arenal VI, igualmente próximo a la ciudad de la $\mathrm{Paz}$ (Figura 2). A diferencia de Arroyo Las Mulas I y Arroyo Largo I que son sitios multipropósitos, Arroyo Arenal VI se conforma como un entierro aislado de objetos (Ceruti 1982,1989), el cual posiblemente integre un sistema de indicadores que delimitan un gran sitio de actividades múltiples, como es el caso de Arroyo Arenal I (Ceruti com. pers.). De este sitio se recuperó uno de los pocos recipientes enteros hallados

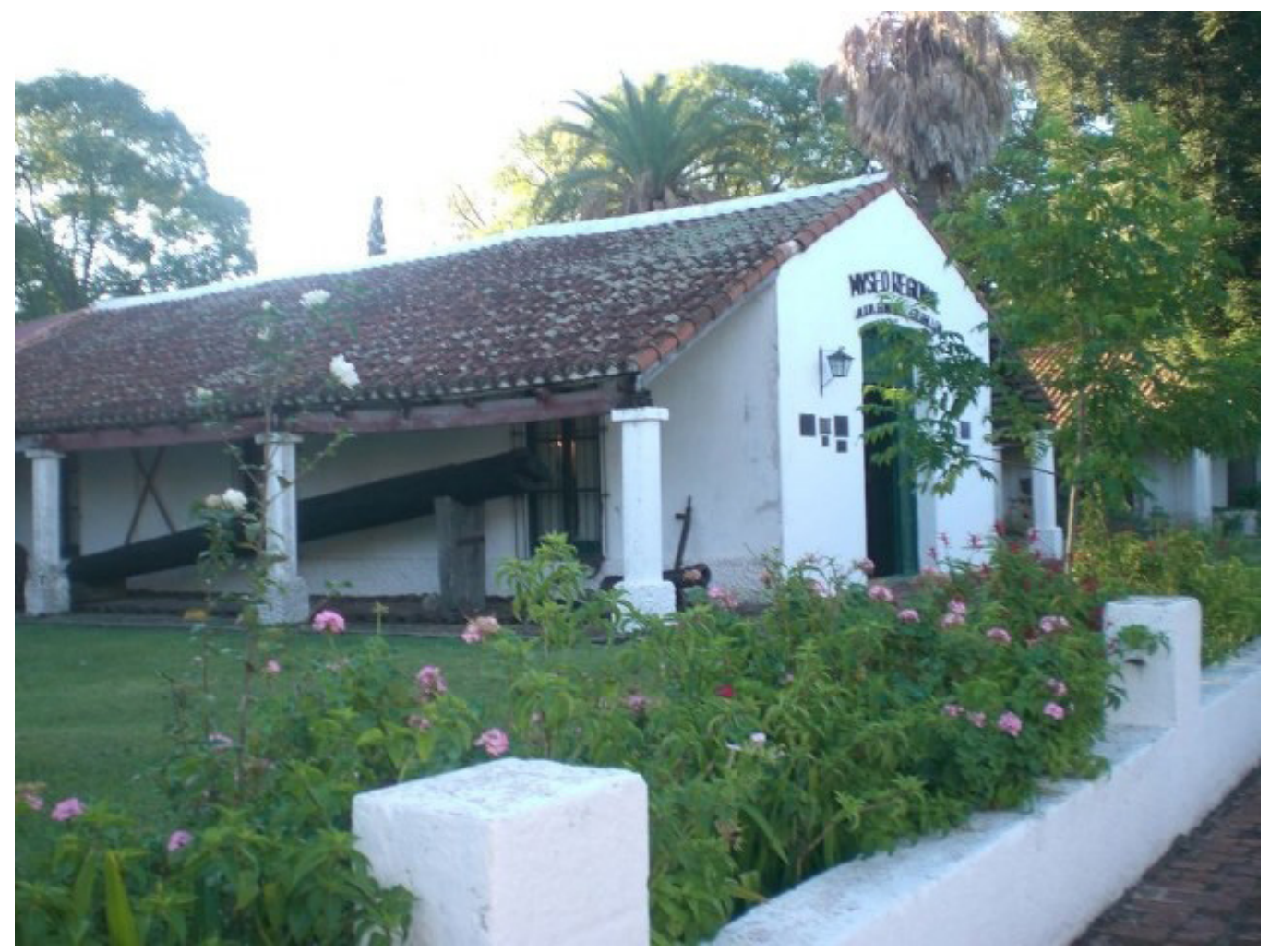

Figura 1. Museo Municipal Regional de La Paz (fuente: Turismo Entre Ríos). 
en la región, cuya descripción e ilustración se incluyen también a continuación. Otras dos de las representaciones zoomorfas que fueron donadas al Museo Regional de La Paz, no cuentan con información precisa sobre su procedencia. Integra la colección, por último, una representación de psitácido procedente del Departamento San Javier, en la provincia de Santa Fe, la única pieza que proviene de la margen derecha del Paraná medio.

En el siguiente anexo se detallan las características decorativas, formales y tecnológicas de las piezas que forman parte de la colección Goya-Malabrigo del Museo Regional de La Paz, las cuales se acompa- ñan de sus dibujos originales. Desde los últimos años, el conocimiento del registro arqueológico Goya-Malabrigo se está ampliando exponencialmente en la arqueología regional (e.g. Barboza y Píccoli 2013; Bonomo et al. 2014; Cornero y Rangone 2015; Loponte y Acosta 2016; Nóbile 1993; Ottalagano 2013, 2015; Sartori 2015; Scabuzzo et al. 2015, entre muchos otros). El relevamiento que presentamos a continuación aportará, sin dudas, nuevos datos al respecto y se constituirá como un valioso material de consulta para las futuras investigaciones en el área.

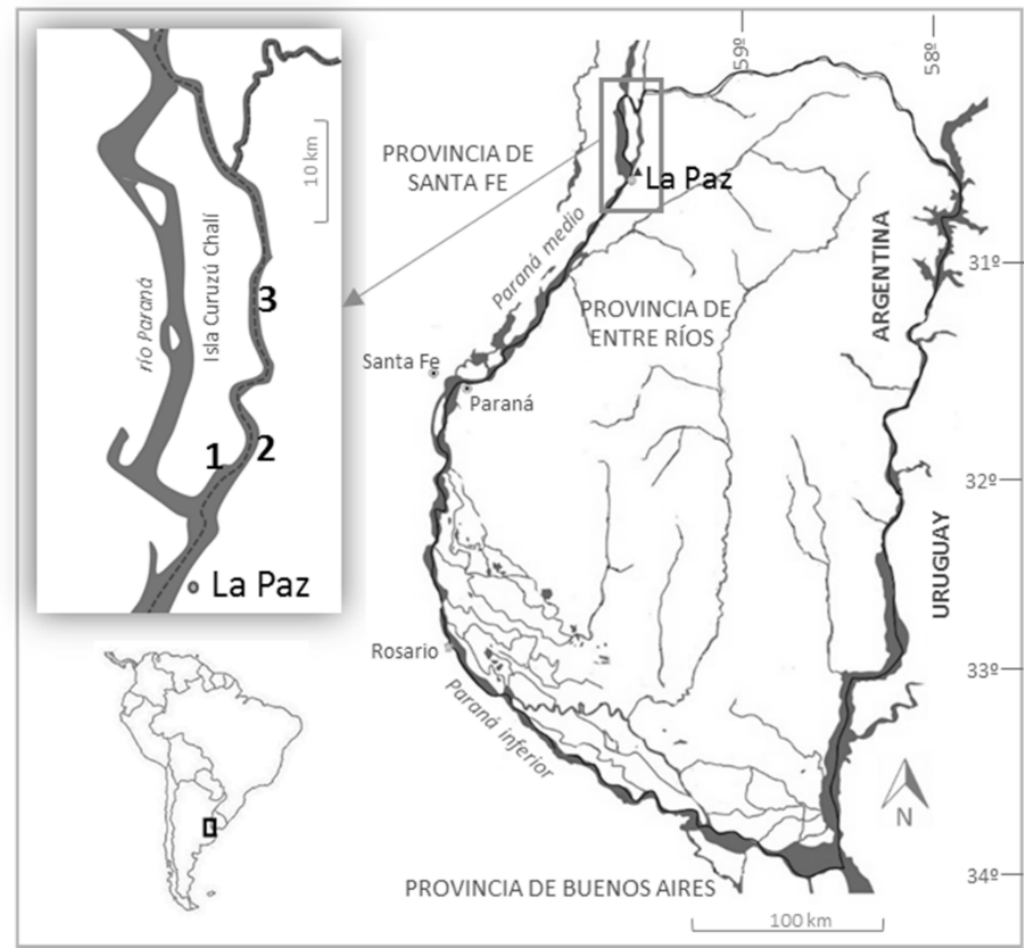

Figura 2. Ubicación de los sitios de procedencia del material relevado: 1) Arroyo Largo I, 2) Arroyo Arenal VI, 3) Arroyo Las Mulas I. 


\section{Bibliografia}

BARBOZA, M.C. y C. PÍCCOLI. 2013. Ocupaciones humanas en la llanura aluvial del Paraná medio durante el Holoceno tardio. El registro arqueológico del sitio Los Bananos (Goya, Corrientes, Argentina). Anuario de Arqueología 5: 117132.

BONOMO, M.; J. C. CASTRO y C. SILVA. 2014. Tecnología y subsistencia en el sitio arqueológico Cerro Tapera Vázquez (Parque Nacional Pre-Delta, República Argentina). Cadernos do LEPAARQ 11: 63-92.

CAGGiANO, M. A. 1984. Prehistoria del N.E. argentino. Sus vinculaciones con la República oriental del Uruguay y sur de Brasil. Pesquisas Antropología 38: 5-109.

CERUTI, C. 1982. Entierros aislados de conjuntos de objetos en el Nordeste argentino. Manuscrito en posesión del autor.

CERUTI, C. 1984. Investigaciones arqueológicas en el área del complejo hidroeléctrico Paraná Medio. Síntomas 8: 20-26.

CERUTI, C. 1989. Proyecto "Las modificaciones ambientales del Pleistoceno final Holoceno, y su relación con los asentamientos humanos en el noroeste de Entre Ríos" (PID-CONICET N ${ }^{\circ}$ 3-081800/88), Informe Final. Manuscrito en posesión del autor.

CERUTI, C. 1990. Sitio Arroyo Las Mulas I (Dpto. La Paz, Provincia de Entre Ríos): aportes para un estudio del ecosistema. Revista de Antropologia 9: 60-67.

CERUTI, C. 1991. Arroyo Las Mulas 1 (Departamento de la Paz, provincia de Entre Ríos): Relaciones hombre medioambiente en la actualidad y alteraciones de sitio por acción antrópica. Revista de Antropología 10: 34-45.

CERUTI, C. 2003. Entidades culturales presentes en la cuenca del Paraná Me- dio (margen entrerriana). Mundo de Antes 3: 111-135.

CORNERO, S. y L. RANGONE. 2015. Análisis arqueobotánicos en sitios de la entidad arqueológica Goya-Malabrigo ubicados en el centro-norte de Santa Fe. Anuario de Arqueología 7: 85-94.

GASPARY, F. 1950. Investigaciones arqueológicas y antropológicas en un "cerrito" de la isla Los Marinos (Dto. Victoria, Entre Ríos) situada frente a Rosario. Publicaciones del Instituto de Arqueología, Lingüistica y Folclore 23: 3-66.

GONZÁlEZ, A.R. 1977. Arte Precolombino de la Argentina. Introducción a su Historia Cultural. Imprenta Coni, Buenos Aires.

LOPONTE, D.M. y A. ACOSTA. 2016. Los contextos Goya-Malabrigo del noreste argentino. Cadernos do CEOM 29(45): 125-187.

NÓBILE, J. 1993. Análisis Arqueofaunísticos del Sitio Arroyo Arenal I, Paraná Medio (Provincia de Entre Ríos). Tesina de Licenciatura en Antropología. Facultad de Humanidades y Artes, Universidad Nacional de Rosario, Rosario.

OTTALAGANO, F.; M. DARIGO; B. PEREYRA; C. BRANCATELLI y L. IANNELLI. 2015. Investigaciones arqueológicas en el sitio La Palmera 2 (cuenca del Paraná medio, provincia de Entre Ríos, nordeste de Argentina). Revista de Antropología del Museo de Entre Ríos 1(1): 55-65.

OTTALAGANO, F. 2008. Hacia la identificación taxonómica de las representaciones de psitácidos en la cerámica de la cuenca del río Paraná. Comechingonia 11:78-98.

OTTALAGANO, F. 2013. Aves simbólicas, Estilo e Identidad en laArqueologia del Gran Rio Sudamericano: Un Estudio Contextual del Arte Cerámico de las Sociedades Prehispánicas de la Cuenca del Río Paraná. Instituto Nacional de 
Ottalagano F. V. - "La colección Goya-Malabarigo del Museo Municipal Regional..."

Antropología y Pensamiento Latinoamericano. Arqueología de la Cuenca del Plata serie monográfica, Buenos Aires.

RODRÍGUEZ, J. 1992. Arqueología del sudeste de Sudamérica. En Prehistoria Sudamericana. Nuevas perspectivas, editado por B. Meggers, pp. 177-209. Taraxacum, Washington-Santiago de Chile.

SARTORI, J. 2015. Ictioarqueología en la llanura aluvial del río Paraná (Santa Fe, Argentina): Los sitios Las Tejas y Pajas Blancas como casos de estudio. Revista Chilena de Antropología 32(2): 73-88.

SCABUZZO, C.; A. RAMOS VAN RAAP; M. BONOMO y G. POLITIS. 2015. Estudios bioarqueológicos en el sitio Los Tres Cerros 1 (Delta Superior del río Paraná, Entre Ríos, Argentina). Boletim do MuseuParaenseEmílioGoeldi 10: 487-518.

SERRANO, A. 1946. Arqueología del Arroyo Las Mulas en el Noroeste de Entre Ríos. Universidad de Córdoba, Córdoba.

SERRANO, A. 1958. Manual de la Cerámica Indigena. Editorial Assandri, Córdoba.

TURISMO ENTRE RÍOS. 2017. http://unatierradiferente.com/historia-y-cultura/ museo-municipal-regional-la-paz-quotalicia-gonzales-castrillonquot.htm 